\title{
Justiciabilidad del derecho a la alimentación. Propuesta teórica y metodológica para el estudio de los derechos sociales $^{1}$
}

\author{
Justiciability of the Right to Food. Theoretical and Methodological Proposal \\ for the Study of Social Rights
}

\author{
César Augusto MolinA-SALDARRIAGA ${ }^{2}$ \\ Olga Cecilia RESTREPO-YEPES ${ }^{3}$ \\ Milton Andrés RoJAS-BETANCUR ${ }^{4}$ \\ Mauricio ZAPATA-OSPINA 5 \\ Luisa Fernanda BEDOYA-TABORDA 6
}

\begin{abstract}
Resumen: Los debates dogmáticos y desarrollos jurídicos sobre el derecho a la alimentación no han contribuido de forma significativa a incrementar sus niveles de satisfacción cualitativa y cuantitativa. Mediante una investigación cualitativa, instrumental, inductiva y de técnica documental se propone un marco teórico y metodológico para la garantía y protección de los derechos, se defiende la justiciabilidad del derecho a la alimentación y, con base en ello, se deconstruyen las principales objeciones a su exigibilidad. Se concluye afirmando que las razones para defender la justiciabilidad del derecho a la alimentación son aplicables a los demás derechos sociales.
\end{abstract}

\footnotetext{
${ }^{1}$ Producto de los diversos proyectos sobre el derecho a la alimentación en los que han participado los autores como investigado res y co-investigadores en sus respectivas instituciones.

${ }^{2}$ Universidad Pontificia Bolivariana. Abogado, especialista en Derecho Administrativo y magíster en Diseño del Paisaje. Medellín, Colombia. Correo electrónico: cesar.molina@upb.edu.co

${ }^{3}$ Universidad de Medellín. Abogada, especialista en Derecho Constitucional, magister en Derecho y doctora en Derecho. Dirección. Medellín, Colombia. Correo electrónico: ocrestrepo@udem.edu.co

${ }^{4}$ Universidad de Medellín. Abogado, magíster en Ciencia Política y doctor en Ciencias Humanas y Sociales. Medellín, Colombia. Correo electrónico: marojas@udem.edu.co

${ }^{5}$ Universidad de Medellín. Abogado y especialista en Derecho Administrativo. Integrante del semillero "Justiciabilidad de los Derechos". Medellín, Colombia. Correo electrónico: mauriciozapataospina@outlook.com

${ }^{6}$ Universidad de Medellín. Abogada y especialista en Derecho Ambiental. Integrante del semillero “Justiciabilidad de los Derech os". Medellín, Colombia. Correo electrónico: luisabedoyat@outlook.com
} 
Palabras clave: Derecho a la alimentación, Exigibilidad, Justiciabilidad, Densidad de los derechos, Derechos sociales

Abstract: Dogmatic debates on the content, structure, components and justiciability of social rights have not contributed to increasing their levels of satisfaction. Likewise, the development of the recognition, guarantee and protection of social rights have not contributed to raising their qualitative and quantitative conditions. From a critical point of view and through a qualitative, instrumental and documentary technique research, a deconstruction of the main objections to the enforceable nature of social rights is carried out: generational and structural. From an explanatory and unified perspective, the right to food is used as a case study to define the existing international and domestic defense means for its protection. Finally, a theoretical and methodological frame of reference is proposed for the complex analysis of social rights. This will make it possible to identify the flaws and propose solutions beyond the merely dogmatic debate on the recognition, guarantee and protection of social rights.

Keywords: Density of Rights, Social Rights, Right to Food, Enforceability, Justiciability

\section{Introducción}

Diversas categorías han sido utilizadas por la doctrina, los ordenamientos jurídicos y la jurisprudencia nacional e internacional, como complemento a la genérica noción de "derechos". Desde clasificaciones generacionales: derechos de primera, segunda y tercera generación; hasta estructurales: derechos fundamentales, sociales, sociales fundamentales, colectivos, innominados, emergentes, entre otros. Sin embargo, resulta cuestionable admitir que la prolífica cantidad de calificativos y categorías existentes incrementan la comprensión y puedan contribuir a la exigibilidad de los derechos. Mejores clasificaciones no convergen a mecanismos idóneos para su satisfacción.

Por el contrario, es frecuente encontrar que aquellas divisiones dificultan entender qué se entiende por los derechos, y puede tener importantes implicaciones prácticas al momento garantizarlos y protegerlos7 ${ }^{7}$ Corresponde a la teoría constitucional ofrecer una visión crítica acerca del alcance de dichas clasificaciones. Así mismo, ofrecer una visión explicativa y unificada sobre la existencia, contenido, validez y justiciabilidad de algunos derechos que han sido reconocidos normativamente durante las últimas décadas y que, en ocasiones, se suponen consolidados.

${ }^{7}$ Cruz (2007), p. 15. 
Afirmamos que las objeciones que han propendido por negar el carácter de justiciables a los derechos sociales o justificar una protección devaluada de los mismos han sido superadas en la teoría y la práctica. La literatura especializada se está inclinando por defender la justiciabilidad de los derechos sociales. Las razones que se exponen para defender esta posición son de naturaleza ideológica — rol de los jueces en democracias-, teórica —contenido de los derechos humanos (DDHH) - y metodológica — decisiones de jueces internacionales y domésticos-. Es por ello que el debate actual se centra en los siguientes problemas: (i) ¿cuál es el alcance que la justiciabilidad de los derechos sociales ha tenido en los órganos internacional, regionales y domésticos de protección de DDHH? (a partir del análisis de casos por sistemas de protección, países o derechos en particular), (ii) ¿cuál es el impacto que la justiciabilidad de los DESC produce en el régimen de separación de los poderes públicos? (control del cumplimiento de las obligaciones de garantía a través de mecanismos de protección) y (iii) ¿cómo medir/valorar la densidad de los derechos a partir de la relación entre las obligaciones de reconocimiento, respeto, garantía y protección de los derechos? Las preguntas (i) y (ii) son de naturaleza metodológica e ideológica, y dan lugar la pregunta (iii) que constituye nuestra propuesta teórica.

Este texto tiene como objetivos ofrecer una síntesis de los fundamentos para defender de la justiciabilidad de los derechos sociales, proponer un marco de referencia teórico y metodológico para el estudio de su garantía y protección, y describir los mecanismos de protección internacional, regional y doméstico del derecho a la alimentación, como caso de estudio. La metodología utilizada para el logro de los objetivos está dentro de la investigación dogmáticojurídica, con enfoque cualitativo y técnica documental. Aplicar la metodología supuso tres procesos: el ejercicio deconstructivo, la prescripción teórica y metodológica, y la realización de un estudio de caso. El primero corresponde a la revisión crítica de la discusión de la exigibilidad de los derechos sociales y una deconstrucción de las objeciones frecuentes que ha planteado la literatura especializada. El segundo, al planteamiento de un marco de referencia teórico y metodológico para analizar el impacto de la justiciabilidad de los derechos sociales en el régimen de separación del poder público y el estudio de la densidad de los derechos. El tercero, a la utilización del derecho a la alimentación como caso concreto para proveer ideas acerca de su exigibilidad. Se trata de un estudio de carácter instrumental ${ }^{8}$ a través del cual se pretende acreditar cómo, en la particularidad del derecho a la alimentación, opera la justiciabilidad de los derechos sociales. Finalmente, se presentan conclusiones y recomendaciones.

${ }^{8}$ Duque et al. (2018). 


\section{Estado del debate sobre la justiciabilidad de los derechos sociales}

Con ánimo de reconstruir el debate sobre la justiciabilidad de los derechos económicos, sociales y culturales —DESC — en la Revista Estudios Constitucionales, se realizó un rastreo de los trabajos publicados en ella. Todos aquellos con los que se trabaja abordan la justiciabilidad de los DESC desde diversos enfoques teóricos y conceptuales. Metodológicamente todos desarrollan investigación dogmática, con enfoque hermenéutico y técnica documental. El primer trabajo rastreado es de Carbonell ${ }^{9}$ y el último trabajo publicado es el de Hamulák, Troitiño y Chochia ${ }^{10}$. Así que puede afirmarse que allá y aquí comienza y va el debate en la Revista.

En relación con los problemas, Carbonell ${ }^{11}$ comienza explicando algunas de las dificultades que enfrentan los juristas al intentar hacer eficaces las normas constitucionales que reconocen derechos sociales y económicos. En conclusión, sostiene que “[...] una teoría constitucional comprometida con la eficacia de los derechos sociales [...]"12 debe subrayar una serie de obligaciones a cargo del poder público. Entre ellas se encuentra la tutela de los derechos sin discriminación, la adopción de medidas para hacer efectivos los derechos del Pacto Internacional de Derechos Económicos, Sociales y Culturales —PIDESC - y la disposición de mecanismos para su protección. En este sentido, el debate sobre la justiciabilidad de los DESC parece partir de la adopción de una perspectiva teórica e ideológica constitucional que defiende su justiciabilidad.

Los problemas sobre los derechos sociales abordados están relacionados con el análisis de su naturaleza, estructura jurídica, fuerza normativa y aplicabilidad inmediata ${ }^{13}$; de la jurisprudencia sobre su protección judicial14; sobre la exigibilidad a la administración y su responsabilidad por la omisión en su garantía15; las implicaciones de su reconocimiento o formalización en instrumentos internacionales respecto de su protección ${ }^{16}$ y el debate sobre algunas perspectivas teóricas que niegan y defienden su justiciabilidad ${ }^{17}$. En relación a las conclusiones que aportan los trabajos revisados pueden identificarse tres posiciones: (i) negar

\footnotetext{
${ }^{9}$ Carbonell (2008).

${ }^{10}$ Hamulák et al. (2018).

${ }^{11}$ Carbonell (2008).

${ }^{12}$ Carbonell (2008), p. 69.

${ }^{13}$ Nogueira (2009) y Pachot (2010).

${ }^{14}$ Martínez (2010), Nash (2011) y Petir (2017).

${ }^{15}$ Wunder (2014).

${ }^{16}$ Hamulák et al. (2018).

${ }^{17}$ Solari y Viera (2015).
} 
su justiciabilidad ${ }^{18}$, (ii) defender su justiciabilidad con límites ${ }^{19}$ y (iii) defender su justiciabilidad en términos absolutos 20 .

Cada una de las posiciones ofrece diversas razones. Respecto de la negación de su justiciabilidad (i), Martínez-Estay ${ }^{21}$ sostiene que los derechos sociales constituyen mandatos a los poderes públicos, particularmente al legislativo, en tanto suponen prestaciones programáticas no exigibles a los Estados. Como consecuencia de su proceso de reconocimiento en las constituciones políticas son considerados garantías institucionales que le permiten un margen de discrecionalidad, dado que no tienen contenido mínimo o esencial, cuyo límite es el respeto del derecho a la igualdad.

Quienes defienden su justiciabilidad limitada (ii) afirman que, a pesar de que las obligaciones que imponen los derechos prestacionales recaen fundamentalmente en la administración y el legislador, existen razones para justificar su protección jurisdiccional no-activista o limitada. La principal razón es el potencial del poder judicial para mejorar dialógica y deliberadamente la democracia. Así, concluyen "[...] que la justiciabilidad de derechos sociales es limitada pero posible, pero que lo es sobre todo si [...] el legislador [y] el administrador [son] inoperante[s], pudiendo así declarar reflexivamente una inconstitucionalidad [...]"22.

Los argumentos para defender su justiciabilidad absoluta (iii) son más sustanciales teóricamente. Algunos sostienen que todos los DDHH deben ser asegurados mediante un contenido constitucional preciso e indisponible por los poderes públicos ${ }^{23}$, en tanto derivan de la dignidad humana ${ }^{24}$; deben contar con mecanismos de garantía amplios (garantía en sentido estricto, como políticas públicas, e.g.) y específicos (protección en sentido estricto, como mecanismos jurisdiccionales, e.g.) ${ }^{25}$, eventualmente, diferenciados; imponen obligaciones prestacionales exigibles judicialmente y a través del control judicial de las políticas públicas²6; esta exigibilidad puede ser inmediata como consecuencia de la multifuncionalidad inherente a todos los derechos fundamentales ${ }^{27}$; y que así lo han reconocido los tribunales internacionales

\footnotetext{
${ }^{18}$ Martínez (2010).

${ }^{19}$ Solari y Viera (2015).

${ }^{20}$ Carbonell (2008), Nogueira (2009), Pachot (2010), Nash (2011), Wunder (2014), Petir (2017) y Hamulák et al. (2018).

${ }^{21}$ Martínez (2010).

22 Solari y Viera (2015), p. 47.

${ }^{23}$ Nogueira (2009).

${ }^{24}$ Nogueira (2009) y Pachot (2010).

${ }^{25}$ Nogueira (2009).

${ }^{26}$ Nash (2011).

27 Wunder (2014).
} 
y domésticos frente a algunos DESC a través de las teorías del "contenido esencial” y del “contenido o derecho al mínimo vital/existencial”28.

De acuerdo con lo anterior, afirmamos dos cosas. Primera, en el debate sobre la justiciabilidad de los derechos sociales en la Revista hay una evidente inclinación a defenderla. Las razones que se exponen para ello son de naturaleza (i) ideológica - el rol de los jueces en la promoción de los derechos y la democracia en los regímenes constitucionales contemporáneos-, (ii) teórica

-indiferencia respecto de los contenidos de los derechos sociales con los derechos civiles y políticos, y la consecuente relación con las obligaciones de protección en unos y otros-, y (iii) metodológica — los tribunales internacionales y domésticos de protección de DDHH y derechos constitucionales así lo han reconocido en sus decisiones-. Segunda, que los autores suelen relacionar la justiciabilidad con la protección judicial o competencias del poder judicial. Sobre esto se harán precisiones en el marco de referencia que se propone.

Ahora, son dos los argumentos teóricos y conceptuales acerca de la exigibilidad de los derechos sociales de los que nos ocuparemos en las siguientes líneas. En ese sentido, se propone revisar críticamente la aparente homogeneidad que estructuran dichos argumentos, que se encuentran amparados por un discurso de corte neoliberal ${ }^{29}$. Al mismo tiempo, advertir que en cada uno de estos se encuentran ciertas falacias argumentativas que han propendido por negar el carácter de exigibles a los derechos sociales o justificar su protección devaluada. Este último argumento íntimamente ligado a una indebida comparación de los derechos sociales con los derechos civiles y políticos.

\section{Un marco de referencia teórico y metodológico para el estudio de la garantía y protección del derecho a la alimentación}

Ofrecimos argumentos en favor de la justiciabilidad de los derechos sociales y, en consecuencia, del derecho a la alimentación. A continuación, presentamos un marco de referencia teórico para el análisis de la relación los contenidos de los derechos, sus vías de satisfacción y las competencias de los poderes públicos, y un marco de referencia metodológico para la evaluación de la densidad de los DDHH en general, y sociales en particular. Queremos,

${ }^{28}$ Nogueira (2010) y Petir (2017).

${ }^{29}$ Cfr. Hayek (1979), Nozick (1974) y Friedman (1962). 
con esto, contribuir al debate de los niveles de satisfacción y a la promoción de estrategias de garantía y protección de derechos sociales en contextos nacionales y regionales.

\subsection{UN MARCO DE REFERENCIA TEÓRICO Y CONCEPTUAL PARA ANALIZAR LA RELACIÓN ENTRE LOS CONTENIDOS DE LOS DERECHOS, SUS VÍAS DE SATISFACCIÓN Y LAS COMPETENCIAS DE LOS PODERES PÚBLICOS}

Los contenidos constitucionales, según Ferrajoli, se distribuyen en dos esferas: indecidible y decidible. La primera describe a un “[...] conjunto de principios que, en democracia, están sustraídos a la voluntad de las mayorías [...]"30, que supone límites a competencias de los poderes públicos, incluso aquellos de origen mayoritario. La segunda refiere a aquello que debe ser decidido o "[...] lo que no puede no ser decidido [...]"31. Ambas esferas son simétricas y complementarias: “[...] sirven para identificar [...], la esfera discrecional de la política, que es propia de [las] 'funciones' e 'instituciones de gobierno', y la esfera vinculada a la sujeción a la ley [denominadas] 'funciones' e 'instituciones de garantía'”.32

La distinción entre esferas y funciones de gobierno y de garantía permite determinar las fuentes de legitimación de cada una de estas funciones. Las de gobierno están dirigidas a la esfera de lo decidible, encuentra su fundamento en la representación democrática -la investidura del voto y la elección popular- y se materializan orgánicamente en los poderes legislativo y ejecutivo - poderes de representación- Las de garantía están dirigidas a la esfera de lo indecidible, encuentran su legitimidad en la rígida sujeción a la ley —carácter cognitivo de sus actividades-, y se materializan orgánicamente en el poder judicial, poderes de control y administración vinculada — poderes de control-

A pesar de la aparente claridad en la formulación ferrajoliana, surgen dudas cuando se reflexiona sobre la forma de determinar el contenido y relación de cada una de las esferas con las competencias de los poderes públicos. La pregunta que surge de esta situación es: ¿cuáles son los contenidos constitucionales que hacen parte de cada una de las esferas? 0, ¿cuáles son los contenidos constitucionales que, incluso en una democracia, están sustraídos a la voluntad de las mayorías y cuáles son los contenidos sobre los cuales no puede dejar de resolverse? Para Ferrajoli la esfera de lo indecidible está constituida por los derechos fundamentales, lo que no obsta para la existencia de obligaciones de carácter positivo frente a ellos y, en ese sentido,

${ }^{30}$ Ferrajoli (2008), p. 337.

${ }^{31}$ Ferrajoli (2008), p. 339.

32 Ferrajoli (2008), p. 339. 
radicadas en los poderes de representación. Sin embargo, no agota una reflexión sobre estos contenidos.

En regímenes constitucionales es posible identificar contenidos que están sustraídos a la voluntad mayoritaria. De un lado, los contenidos mínimos del constitucionalismo: la separación del poder público, el régimen de libertades y garantías, y el régimen democrático ${ }^{33}$. Derivado de aquellos contenidos se identifican como sustraídos a las funciones de gobierno los derechos fundamentales y de las minorías, los contenidos negativos o núcleo esencial de los derechos subjetivos y las cláusulas pétreas, principios intangibles o elementos definitorios del régimen constitucional $^{34}$. Finalmente, puede ubicarse dentro de la esfera de lo indecidible la obligación de decidir.

Frente al régimen de derechos subjetivos, hará parte de la esfera de lo indecible su contenido negativo, y hará parte de la esfera de lo decidible su contenido positivo. Esto es determinante para analizar las obligaciones que se derivan para las autoridades de la relación jurídica que se establece entre el Estado y los individuos en virtud de los DDHH. La dimensión negativa implica la existencia de deberes/obligaciones de abstención o no-hacer y la dimensión positiva deberes/obligaciones de acción, de hacer o de dar.

Las obligaciones que derivan para el Estado de la relación jurídica que se establece con el individuo por los DDHH son el reconocimiento, el respeto, la garantía y la protección. La de reconocimiento implica incorporar los derechos en los ordenamientos jurídicos internos, como mecanismo de creación de las condiciones formales para la satisfacción de las necesidades, y se cumple mediante la suscripción de instrumentos internacionales, el reconocimiento constitucional y el desarrollo legal o reglamentario. La de respeto impone restricciones de acción al Estado respeto del ámbito de libertad reconocido por el ordenamiento jurídico al titular del derecho; esto es, la no-violación o no-vulneración del derecho; de allí que se trate de una obligación de no-hacer que incluye la de no-decidir. La de garantía conmina al Estado a crear las condiciones de posibilidad materiales para ejercer el derecho mediante el cumplimiento de obligaciones de aseguramiento y promoción; lo que trae consigo la obligación de decidir. La obligación de protección implica que, ante la violación o vulneración del derecho — por decidir

\footnotetext{
${ }^{33}$ Ferrajoli $(1995 ; 2007)$ y Fioravanti (2014)

${ }^{34}$ Cfr. Corte Constitucional de Colombia (Sentencias C-053, 2016; C-1200, 2003; C-153, 2007; C-588, 2009; C-010, 2013; C-579, 2013, y C-288, 2012).
} 
sobre lo indecidible o no decidir sobre lo decidible - el Estado debe determinar el hecho, el daño y el responsable, y ordenar la reparación, indemnización o restablecimiento.

Tabla 1. Contenido de las obligaciones estatales frente a los derechos

\begin{tabular}{l|lll}
\hline \multicolumn{1}{c|}{ Obligación } & \multicolumn{3}{|c}{ Contenido } \\
\hline Reconocimiento & $\begin{array}{l}\text { Incorporar al ordenamiento } \\
\text { jurídico }\end{array}$ & \\
\hline Respeto & $\begin{array}{l}\text { Abstenerse de violentar el } \\
\text { derecho }\end{array}$ & \\
\hline Garantía & $\begin{array}{l}\text { Crear condiciones para el } \\
\text { ejercicio del derecho }\end{array}$ \\
\hline Protección & $\begin{array}{l}\text { Sancionar las violaciones del } \\
\text { derecho }\end{array}$ \\
\hline
\end{tabular}

Fuente: elaboración propia

Finalmente, la obligación de respeto desarrolla la dimensión negativa, la obligación de garantía la dimensión positiva, y las obligaciones de reconocimiento y protección son transversales.

Gráfico 1. Dimensiones de los derechos y obligaciones estatales frente a los derechos

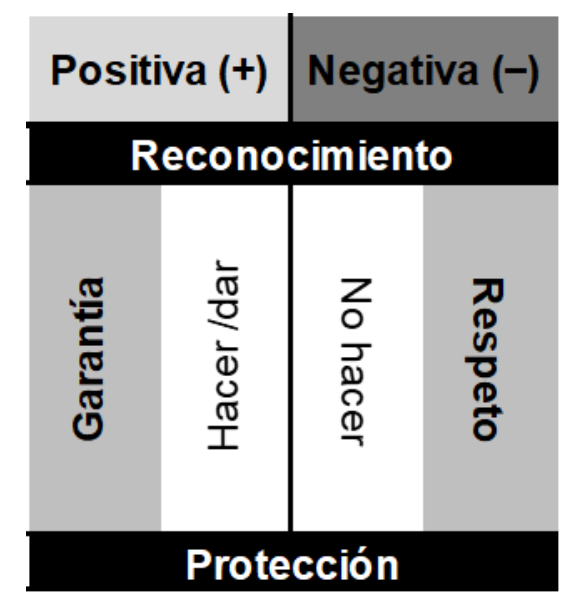

Fuente: elaboración propia

De las obligaciones derivan las vías de satisfacción de los derechos: estructura y emergencia. De la obligación de garantía deriva la vía de la estructura y de la obligación de protección procede la vía de la emergencia. A través de la primera. el Estado crea condiciones de posibilidad 
materiales para la satisfacción del derecho y lo hace, fundamentalmente, a través de la implementación de políticas públicas. Por su parte, la vía de la emergencia opera cuando se incumplen obligaciones de respeto y garantía. Frente a esto, puede ser que la vía de la estructura no exista o falle. La inexistencia implica un incumplimiento del deber de decidir. La falla puede obedecer a factores endógenos o exógenos de la política. En cualquier caso, los poderes de control intervienen a través de mecanismos judiciales, cuasi-judiciales o administrativos para asegurar que los contenidos indecidibles no sean desconocidos por los poderes públicos.

La propuesta teórica y conceptual que se presenta reconoce las clasificaciones que se han realizado sobre los derechos. Dos de las más autorizadas y bastante debatidas son las de Ferrajoli ${ }^{35}$ y Alexy ${ }^{36}$. El primero distingue entre derechos negativos y positivos. Los primeros constituidos por libertades y autonomías. Los segundos, por los derechos sociales. Sobre estos últimos, Ferrajoli reconoce que “[...] consisten principalmente en expectativas positivas”, pero también incluyen "[...] expectativas negativas de no lesión”37. Así mismo, reconoce que estas últimas no plantean mayores problemas ante sus garantías primarias - obligaciones de garantía- y secundarias —obligaciones de protección- "Los mayores problemas relativos a los derechos sociales — sostiene Ferrajoli- son [...] los generados por su forma lógica de expectativa positivas universales y por las garantías positivas que estás requieren"38. Entre otros, resalta su onerosidad. Y, en segundo lugar, el de las garantías secundarias — justiciabilidad en nuestros términos- “[...] relativo a la determinación y la remoción o reparación de las lagunas primarias de garantías y de la consiguiente inefectividad estructural de los correspondientes derechos"39. Ferrajoli ha resuelto este problema afirmando las dificultades que supone el ejercicio de garantías secundarias ante el incumplimiento de la garantía primaria de la expectativa positiva de los derechos sociales y, de allí, la imposibilidad de ejercerla. En síntesis, negando su justiciabilidad.

Por su parte, Alexy distingue entre derechos a acciones negativas o de defensa y derechos a acciones positivas del estado o a prestaciones en sentido amplio. Los últimos divididos en derechos a protección, derechos a organización y procedimiento y derechos a prestaciones en sentido estricto, que son los derechos sociales fundamentales. Ante esta distinción, reduce la

\footnotetext{
${ }^{35}$ Ferrajoli (2007).

${ }^{36}$ Alexy (1993).

${ }^{37}$ Ferrajoli (2007), p. 384.

${ }^{38}$ Ferrajoli (2007), p. 385.

${ }^{39}$ Ferrajoli (2007), p. 388.
} 
problemática de la justiciabilidad de los derechos sociales a uno de ponderación entre principios. 40

Ambas propuestas no satisfacen la necesidad de justiciabilidad de los derechos sociales. Las discriminaciones analíticas que proponen no son suficientes para afirmar la diferencia estructural entre derechos civiles y políticos, y derechos sociales y económicos, ni negar la justiciabilidad de los últimos. Advertido esto, presentamos una propuesta teórica, conceptual y metodológica. La última incorpora tres elementos: dogmático, jurídico y fáctico. En el dogmático distinguimos para todos los derechos subjetivos su dimensión negativa y positiva, y defendemos su justiciabilidad, incluso para aquellos que analíticamente se distinguen como sociales.

\subsection{ELEMENTOS METODOLÓGICOS PARA LA EVALUACIÓN DE LA DENSIDAD DE LOS DERECHOS}

Desde un enfoque garantista defendemos la justiciabilidad de los derechos sociales. Ello se sustenta en la existencia de fundamentos teóricos y dogmáticos estables y continuos que propugnan por su defensa, tanto en la doctrina como en los medios de divulgación arbitrados. Así mismo, hay evidencia de su articulación en los ordenamientos jurídicos por medio del reconocimiento y la protección — como se presentará más adelante para el caso del derecho a la alimentación- En este escenario identificamos la siguiente pendiente y fértil área de investigación: ¿a través de qué concepto analítico podemos analizar de forma conjunta los factores dogmáticos y empíricos de los derechos, como parte de un mismo fenómeno jurídico y político? El concepto que proponemos es: densidad de los derechos.

En la física y la química la densidad "expresa la relación entre la masa y el volumen de un cuerpo"41. La masa expresa su cantidad de materia y el volumen su extensión en tres dimensiones, largo, ancho y alto ${ }^{42}$. De esta relación, se afirma que un cuerpo es más denso que otro cuando su materia ocupa menor extensión en relación con otro cuerpo. En relación con el agua, un cuerpo será más o menos denso que ella en la medida en que se hunda o flote, respectivamente.

¿A qué aludimos con este concepto y a qué contribuye? En primer lugar, se pretende determinar el nivel de concreción de un derecho en su contexto empírico. Es decir, la relación existente entre los niveles de satisfacción de un derecho (elemento fáctico) y su reconocimiento,

\footnotetext{
${ }^{40}$ Alexy (1993), p. 494.

${ }^{41}$ Real Academia Española (2019).

42 Real Academia Española (2019).
} 
garantía y protección (elemento jurídico), a partir de los acuerdos dogmáticos sobre su contenido, estructura y componentes (elemento dogmático). El elemento fáctico constituye la masa, mientras el elemento jurídico constituye el volumen. El elemento dogmático determina los indicadores que han de levantarse en relación con los elementos fáctico y jurídico. Así, la densidad del derecho será baja o alta en la medida en que los indicadores empíricos del elemento fáctico den cuenta de bajos o altos niveles de satisfacción, respectivamente, en el contexto de los elementos jurídicos. Estos se valoran a partir de datos determinados por el contenido, estructura y componentes del derecho definidos por el elemento dogmático. Los análisis que derivarían de este tipo de estudios podrían aludir a la situación y comportamiento de un derecho en el tiempo y en el espacio, y su comparación con otros derechos o en otros ordenamientos jurídicos.

\section{Gráfico 2. Elementos y componentes de la densidad de los derechos}

$$
\text { Densidad del derecho }=\frac{\text { Masa del derecho }}{\text { Volumen del derecho }}
$$

Masa del derecho= Elemento fáctico. Constituida por datos empíricos que dan cuenta del nivel de satisfacción del derecho. El nivel de satisfacción depende del contenido, estructura y componentes del derecho definidos por el elemento dogmático.

Volumen del derecho $=$ Elemento jurídico. Constituido por los niveles de reconocimiento, garantía y protección del derecho. Estos se representan por la existencia de disposiciones normativas que reconozcan el derecho (instrumentos internacionales y de derecho interno), la disposición de instrumentos de garantía (políticas públicas) y mecanismos de protección (judiciales, cuasijudiciales o administrativos) y la existencia de decisiones sobre la protección del derecho.

\section{Fuente: elaboración propia}

Argumentamos que los tres procesos — dogmático, jurídico y fáctico- son diferenciales e independientes, pero no separables: los argumentos dogmáticos y jurídicos de un derecho no hacen eludible el análisis de su concreción fáctica. Apreciar los acuerdos dogmáticos que hay sobre un derecho, las normas que lo reconocen, los instrumentos que lo garantizan o las decisiones que lo protegen, no dice nada sobre su satisfacción en el plano fáctico. 


\section{Mecanismos internacionales y domésticos de protección del derecho a la alimentación}

La consideración sobre los mecanismos existentes que buscan hacer exigibles los derechos sociales supone aceptar la tesis de que es posible defender las exigencias de justicia que suponen. Resulta pertinente destacar que, a pesar de los desarrollos teóricos, normativos y jurisprudenciales por fortalecer el contenido de los derechos sociales, los mismos no parecen ir ligados a los progresos realizados a su efectiva materialización y exigibilidad. El derecho a la alimentación no está exento de esta abismal realidad. Consideremos dos estadísticas fundamentales para el caso colombiano: los resultados presentados durante los últimos años por la Encuesta Nacional de la Situación Nutricional en Colombia —ENSIN — con respecto al estado de malnutrición en la vida de los colombianos ${ }^{43}$, y los registros oficiales del Departamento Administrativo Nacional de Estadística - DANE - en lo relativo al padecimiento del hambre y desnutrición. ${ }^{4}$

Según los resultados de la ENSIN para 2005 el 40.8\% de los colombianos se encontraba en estado de inseguridad alimentaria ${ }^{45}$. En 2010 hubo un incremento de 1.9 puntos $(42.7 \%)^{46}$. Para 2015 la inseguridad alimentaria en el hogar ascendía al 54,2\%47. En relación al padecimiento del hambre y desnutrición, los registros oficiales del DANE indican que el número de defunciones en Colombia por causas asociadas a la desnutrición entre los años de 1979 a 1989 fueron en promedio 2376,45 casos. Entre los años de 1990 a 1999 fueron en promedio 1444,1 casos y entre los años de 2000 a 2009 y 2010 a 2016 incrementó en un promedio de 1949,3 y 1705,14 casos, respectivamente ${ }^{48}$.

Los datos presentados dan cuenta de la brecha fáctica entre la regulación normativa ("deber ser") y la realidad física ("ser"). De allí que las tesis dogmáticas y las sociológicas resulten, en la mayoría de los casos, virtualmente divergentes. Advertir la existencia de dos puntos distantes, la norma y la realidad, y establecer las herramientas que permiten a los individuos y las comunidades vulnerables la justiciabilidad de los derechos, resulta ser una tarea obligada. Por esto, la segunda parte del presente artículo se ocupa se describir los mecanismos de protección

\footnotetext{
${ }^{43}$ Instituto Colombiano de Bienestar Familiar (2006, 2011 y 2020).

${ }^{44}$ Departamento Administrativo Nacional de Estadística (s.f.).

45 Instituto Colombiano de Bienestar Familiar (2006).

46 Instituto Colombiano de Bienestar Familiar (2011).

47 Instituto Colombiano de Bienestar Familiar (2020).

48 Departamento Administrativo Nacional de Estadística (s.f.).
} 
que procuran la justiciabilidad y exigibilidad del derecho a la alimentación en el derecho internacional y doméstico.

El derecho a la alimentación en el ordenamiento jurídico colombiano fue tradicionalmente reglamentado en un nivel infra constitucional bajo la denominación de "el derecho de alimentos". Posteriormente, reconociendo el valor que se le había asignado en el PIDESC, la Constitución Política colombiana vigente incluyó el derecho a la alimentación en el Capítulo II "De los derechos sociales, económicos y culturales" en sus artículos 43, 44, 46 y 65 . Este reconocimiento introdujo en el ordenamiento jurídico un conjunto de garantías de carácter constitucional, cuyo contenido dogmático ha sido decantado por la jurisprudencia y por las interpretaciones efectuadas por los órganos en el nivel internacional ${ }^{49}$. A partir de los avances jurisprudenciales y lineamientos internacionales frente al derecho a la alimentación, se comprende que su contenido se encuentra compuesto por tres elementos esenciales: la disponibilidad, la accesibilidad y la adecuación de los alimentos ${ }^{50}$.

Admitiendo que la construcción del derecho a la alimentación se ha desarrollado en los planos internacional y nacional, son estas las vías de justiciabilidad que se analizan.

\subsection{JUSTICIABILIDAD DEL DERECHO A LA ALIMENTACIÓN EN EL SISTEMA UNIVERSAL DE PROTECCIÓN DE DERECHOS HUMANOS}

En el ámbito internacional el documento fundante sobre derechos sociales es el Pacto Internacional de Derechos Económicos, Sociales y Culturales -PIDESC-51, vigilado por el Consejo Económico y Social de la Organización de las Naciones Unidas -ECOSOC—. Este creó el Comité de Derechos Económicos, Sociales y Culturales - CESCR—52, quien tiene competencia para revisar informes presentados por Estados parte en el PIDESC y hacer recomendaciones de carácter general a partir de aquellos y de informes presentados por organismos especializados. El CESCR apoya al ECOSOC en el cumplimiento de sus responsabilidades, como, la emisión de recomendaciones generales y la aplicación efectiva y progresiva del PIDESC —artículos 21 y 22-. Así, contribuye a precisar el contenido y alcance de los derechos previstos en el PIDESC y las obligaciones que recaen sobre los Estados en virtud de él.

\footnotetext{
49 Organización de las Naciones Unidas para la Agricultura y la Alimentación (2004) y Comité de Derechos Económicos, Sociales y Culturales (1999).

${ }^{50}$ Comité de Derechos Económicos, Sociales y Culturales (1999).

${ }^{51}$ Naciones Unidas (1966).

52 Resolución 1985/17-Consejo Económico y Social de las Naciones Unidas (1985).
} 
En cumplimiento de este objetivo se otorgó al Comité competencias para el desarrollo, entre otras, de tres funciones: recibir y examinar los informes periódicos de implementación del Pacto en el orden interno que presente cada uno de los Estados miembros ${ }^{53}$, interpretar los derechos $\mathrm{y}$ obligaciones contenidos en el Pacto y recibir y conocer las denuncias o quejas de los particulares ${ }^{54}$. El ejercicio de esta última función se encuentra supeditada a que los Estados parte suscriban el Protocolo Facultativo del PIDESC. Ello porque la entrada en vigor de la competencia para conocer de quejas individuales requiere de un número determinado de Estados que ratifique el instrumento internacional, que a la fecha no ha sido satisfecho. En consecuencia, el Comité no está facultado para admitir y tramitar denuncias individuales por presuntas violaciones a los derechos reconocidos en el Pacto. En últimas, la justiciabilidad del derecho a la alimentación en el Sistema Universal se encuentra limitada.

Por otro lado, Colombia reconoce la competencia al Comité para la Eliminación de todas las Formas de Discriminación contra la Mujer —CEDAW, por sus siglas en inglés-y al Comité de los Derechos del Niño para conocer de quejas individuales. Los tratados que aplican e interpretan estos contemplan importantes derechos en materia alimentaria. En caso de inobservancia de las obligaciones que derivan del derecho a la alimentación se activa la vía directa de queja o denuncia ante dichos organismos. De la Convención sobre la eliminación de todas las formas de discriminación contra la mujer ${ }^{55}$ cabe destacar los artículos 12 y 14 que protegen los derechos de las madres y los lactantes a la alimentación, y los derechos de las mujeres que habitan en zonas rurales contra la discriminación en el acceso a los recursos productivos $^{56}$, respectivamente. De otro lado, la Convención sobre los Derechos del Niño ${ }^{57}$ protege el derecho a la alimentación en los artículos 24 y 27, que reconocen los derechos a la salud y el nivel de vida adecuado, respectivamente. Ambos Comités componen una posible estructura de defensa del derecho a la alimentación desde el Sistema Universal.

\subsection{JUSTICIABILIDAD DEL DERECHO A LA ALIMENTACIÓN EN EL SISTEMA INTERAMERICANO DE PROTECCIÓN DE DERECHOS HUMANOS}

Se describe a continuación la justiciabilidad del derecho a la alimentación en el Sistema Interamericano de Protección de Derechos Humanos, competente para conocer de la violación

\footnotetext{
${ }^{53}$ Naciones Unidas (1966).

${ }^{54}$ Naciones Unidas (2008), Artículo primero del Protocolo Facultativo.

${ }^{55}$ Naciones Unidas (1979).

${ }^{56}$ El mecanismo para la presentación de denuncias ante el Comité se encuentra contenido en el Protocolo Facultativo de las Naciones Unidas de la Convención sobre la Eliminación de todas las formas de Discriminación contra la Mujer (1999), el cual fue ratificado por Colombia por Colombia el 23 de enero de 2007.

${ }^{57}$ Naciones Unidas (1989).
} 
de los DDHH consagrados en los instrumentos regionales para Colombia. Ello supone la existencia de una regulación del derecho a la alimentación en los instrumentos internacionales que componen dicho sistema, un organismo encargado de la protección de estos y recursos o mecanismos que permitan a los titulares del derecho defenderse ante eventuales vulneraciones. ${ }^{58}$

Sobre el primer punto, la Declaración Americana de Derechos y Deberes del Hombre ${ }^{59}$ y la Convención Americana sobre Derechos Humanos - $\mathrm{CADH}-60$ no contemplan un reconocimiento expreso del derecho a la alimentación. Sin embargo, el Protocolo Adicional a la CADH en materia de DESC "Protocolo de San Salvador"61 consagra de manera directa en su artículo 12 el derecho a la alimentación.

Sobre la existencia de organismos encargados de velar por la protección del derecho a alimentación, son dos los existentes al interior del sistema regional: la Comisión Interamericana de Derechos Humanos - CIDH - y la Corte Interamericana de Derechos Humanos - Corte IDH- Ambas fueron creadas, de acuerdo con el artículo 33 de la Convención, con el propósito de "[...] conocer de los asuntos relacionados con el cumplimiento de los compromisos contraídos por los Estados Parte en [la] Convención". La Comisión tiene como funciones estimular la conciencia de los DDHH, formular recomendaciones, preparar estudios e informes, solicitar informes, atender consultas, actuar respecto de las peticiones y otras comunicaciones, y rendir un informe anual a la Asamblea General de la Organización de los Estados Americanos, de acuerdo con el artículo 41 de la Convención. A la Corte le compete, de acuerdo con el artículo 62.3 convencional, “[...] conocer de cualquier caso relativo a la interpretación y aplicación de las disposiciones de esta Convención que le sea sometido [...]".

Se prevé la denuncia individual de violación de DDHH ante la CIDH como mecanismo central de protección de los derechos convencionales. Ella puede remitir el caso a la Corte para que se pronuncie sobre el asunto cuando el Estado no cumple con las recomendaciones hechas por ella. La Corte se ha pronunciado en diversas ocasiones sobre la violación del derecho a la alimentación. Entre ellos, en el caso de los indígenas ${ }^{62}$, personas privadas de la libertad ${ }^{63}$ y

\footnotetext{
${ }^{58}$ Cfr. Golay (2009).

${ }^{59}$ Organización de Estados Americanos (1948).

60 Organización de Estados Americanos (1969).

${ }^{61}$ Organización de Estados Americanos (1988).

${ }^{62}$ Corte Interamericana de Derechos Humanos (2005).

${ }^{63}$ Corte Interamericana de Derechos Humanos $(2006 ; 2010 ; 2012)$.
} 
desplazados forzados por la violencia ${ }^{64}$, directamente a partir del artículo 12 del Protocolo de San Salvador, o en relación con la violación de los derechos a la vida y la integridad personal reconocidos en los artículos 4 y 5 de la Convención Americana.

En el caso de las comunidades indígenas, sostiene la Corte que las violaciones del derecho a la alimentación están íntimamente ligadas con la violación de los derechos a la salud y el agua e impactan el derecho a una existencia digna y las condiciones para el ejercicio de otros derechos ${ }^{65}$. Sobre las personas privadas de la libertad, sostiene que es obligación del Estado asegurarles alimentación ${ }^{66}$, que las condiciones de hacinamiento obstaculizan su satisfacción ${ }^{67}$ y que la calidad y valor nutritivo de los alimentos suministrados en los establecimientos carcelarios hace parte de los estándares de sus condiciones ${ }^{68}$. En relación con las víctimas de desplazamiento, sostiene que es uno derecho sistemáticamente vulnerado en estas situaciones ${ }^{69}$.

En reciente sentencia ${ }^{70}$ la Corte sostiene explícitamente que los Estados tienen el deber de respetar, garantizar y proteger el derecho a la alimentación ${ }^{71}$. Frente a la obligación de garantía, en la Opinión Consultiva OC-23/17 afirma que, en casos de personas que no estén en condiciones de acceder por si mismas a agua y alimentación, los Estados deben garantizarles un mínimo esencial ${ }^{72}$. Sobre la obligación de protección, valiéndose de la Observación General N. $12^{73}$, afirma que los Estados deben adoptar medidas para evitar que los particulares priven a las personas del acceso a una alimentación adecuada y que el derecho es vulnerado por el Estado cuando no controla "[...] las actividades de individuos o grupos para evitar que violen el derecho a la alimentación de otras personas"74. Con base en sus consideraciones la Corte en la parte resolutiva de la sentencia ordena al Estado, entre otras, presentar "[...] un estudio en que identifique situaciones críticas de falta de acceso a agua potable o alimentación [...]” y formular e implementar “[...] un plan de acción, en los términos señalados en los párrafos 332 y 343 de la [...] Sentencia"75.

\footnotetext{
${ }^{64}$ Corte Interamericana de Derechos Humanos (2013).

${ }^{65}$ Corte Interamericana de Derechos Humanos (2005) párr. 167.

${ }^{66}$ Corte Interamericana de Derechos Humanos (2006) párr. 146.

${ }^{67}$ Corte Interamericana de Derechos Humanos (2010).

${ }^{68}$ Corte Interamericana de Derechos Humanos (2012) párr. 67.

${ }^{69}$ Corte Interamericana de Derechos Humanos (2013) párr. 323 y 330.

${ }^{70}$ Corte Interamericana de Derechos Humanos (2020).

${ }^{71}$ Corte Interamericana de Derechos Humanos (2020) párr. 221.

${ }^{72}$ Corte Interamericana de Derechos Humanos (2017) párr. 121

73 Comité de Derechos Económicos, Sociales y Culturales (1999).

${ }^{74}$ Corte Interamericana de Derechos Humanos (2020) párr. 221.

75 Corte Interamericana de Derechos Humanos (2020) pág. 122.
} 


\subsection{JUSTICIABILIDAD DEL DERECHO A LA ALIMENTACIÓN EN LA JURISDICCIÓN CONSTITUCIONAL COLOMBIANA}

La Constitución Política colombiana consagra el principio de supremacía constitucional en su artículo 4. En virtud de que la Constitución es criterio de validez formal y material, y legitimidad de las demás normas del orden jurídico; sus disposiciones prevalecen sobre las demás normas del ordenamiento y es deber de todos acatar las disposiciones constitucionales, se consagran mecanismos de control y protección. Colombia adopta un modelo mixto de control constitucional, disponiendo un control concentrado en manos de la Corte Constitucional y difuso en manos de las demás autoridades. En ejercicio del control concentrado la Corte ejerce un control abstracto a través de la acción de inconstitucionalidad y concreto a través de la revisión de las sentencias de tutela. En el presente apartado describiremos estos mecanismos de control constitucional y revisaremos algunas decisiones de la Corte sobre la justiciabilidad del derecho a la alimentación.

La acción pública de inconstitucionalidad es el mecanismo en virtud del cual los ciudadanos acuden ante la Corte para que decida si un acto legislativo, una ley o un decreto de contenido legislativo es violatorio de la Constitución. En este sentido, la acción pública de inconstitucionalidad hace justiciable el derecho a la alimentación en aquellos eventos en que el mismo sea vulnerado por disposiciones legales o reglamentarias. Mediante el control abstracto de constitucionalidad la Corte ha protegido el derecho a la alimentación, entre otros, en el caso de desplazados y migrantes ${ }^{76}$, y comunidades campesinas ${ }^{77}$.

Respecto a la población desplazada por la violencia, la Corte ha afirmado que el derecho a la alimentación es fundamental y que las obligaciones alimentarias a cargo del Estado hacen parte del contenido esencial del derecho a la asistencia humanitaria ${ }^{78}$. Frente a las comunidades campesinas ha señalado que la realización del derecho a la alimentación hace parte de los derechos sociales ${ }^{79}$ y se encuentra ligado con: el aprovechamiento de su propia tierra; el respeto de sus formas tradicionales de producción y la garantía de sus necesidades básicas y la protección frente a los efectos del desarrollo agroindustrial ${ }^{80}$.

\footnotetext{
${ }^{76}$ Corte Constitucional de Colombia, Sentencia C-255 (2003).

77 Corte Constitucional de Colombia, Sentencias C-077 (2017) y C-371 (2014).

${ }^{78}$ Corte Constitucional de Colombia, Sentencia C-255 (2003).

${ }^{79}$ Corte Constitucional de Colombia, Sentencia C-371 (2014).

${ }^{80}$ Corte Constitucional de Colombia, Sentencia C-077 (2017).
} 
La acción de tutela es un mecanismo de control concreto de constitucionalidad previsto en el artículo 86 de la Constitución. Su objeto es proteger los derechos fundamentales cuando acciones u omisiones de las autoridades o de los particulares pueden afectarlos. Conforme al artículo 241.9 de la Constitución, corresponde a la Corte revisar las decisiones judiciales relacionadas con la acción de tutela que emitan los demás jueces. Respecto del carácter fundamental de un derecho, en el régimen constitucional colombiano se han reconocido 5 criterios: formal, conexidad, mínimo vital, sujetos de especial protección constitucional y núcleo esencial. El derecho a la alimentación no es un derecho formalmente fundamental, su protección mediante control concreto de constitucionalidad se ha logrado por conexidad y en situaciones de desprotección de sujetos de especial protección: niñas y niños ${ }^{81}$, mujeres en estado de embarazo y lactancia ${ }^{82}$, ancianos ${ }^{83}$, internos en establecimientos carcelarios ${ }^{84}$ y comunidades indígenas y campesinas ${ }^{85}$.

Sobre la protección del derecho a la alimentación de niñas y niños, sostiene la Corte que deriva de la condición humana ${ }^{86}$ y es fundamental ${ }^{87}$. Por su parte, frente a las mujeres en estado de embarazo y lactantes, la gravidez y el desempleo obligan al Estado a la asistencia y protección de ellas, y a prestar subsidio alimentario ${ }^{88}$; y este subsidio constituye un derecho fundamental 89. Respecto a adultos mayores considera que la alimentación hace parte de su calidad de vida ${ }^{90}$. Por otro lado, en situación de indigencia — como lo prevé el artículo 46 constitucional- el derecho a la alimentación obliga al Estado al otorgamiento del subsidio alimentario como manifestación del principio de solidaridad ${ }^{91}$. Finalmente, el incumplimiento de esta obligación implica la violación de derechos fundamentales, como el mínimo vital y la igualdad ${ }^{92}$.

En relación con las personas privadas de la libertad, sostiene la Corte que la condición en la que se encuentran supone la privación y limitación de ciertos derechos y el surgimiento de otros derechos derivados del ordenamiento jurídico penitenciario, como el derecho a la alimentación ${ }^{93}$. Entre otras, dispone que el derecho a la alimentación adecuada hace parte del

\footnotetext{
${ }^{81}$ Corte Constitucional de Colombia, Sentencias T-0081(992), T-339 (1993) y T-049 (1995).

${ }^{82}$ Corte Constitucional de Colombia, Sentencias T-179 (1993) y T-373 (1998).

${ }^{83}$ Corte Constitucional de Colombia, Sentencias T-426 (1992), T-029 (2001), T-523 (2006) y T-1031 (2004).

${ }^{84}$ Corte Constitucional de Colombia, Sentencias T-424 (1992) y T-714 (1996).

85 Corte Constitucional de Colombia, Sentencias T-348 (2012) y T-256 (2015).

${ }^{86}$ Corte Constitucional de Colombia, Sentencia T-008 (1992).

${ }^{87}$ Corte Constitucional de Colombia, Sentencia T-049 (1995).

${ }^{88}$ Corte Constitucional de Colombia, Sentencia T-179 (1993).

${ }^{89}$ Corte Constitucional de Colombia, Sentencia T-373 (1998).

${ }^{90}$ Corte Constitucional de Colombia, Sentencia T-426 (1992).

${ }^{91}$ Corte Constitucional de Colombia, Sentencias T-029 (2001) y T-523 (2006).

92 Corte Constitucional de Colombia, Sentencia T-1031 (2004).

93 Corte Constitucional de Colombia, Sentencia T-424 (1992).
} 
derecho al mínimo vital del interno. Se trata de un derecho fundamental cuyo contenido está definido porque la alimentación que reciba “[...] responda, en cantidad y calidad, a prescripciones dietéticas o de higiene que garanticen, al menos, sus necesidades básicas de nutrición"94.

En relación con las comunidades indígenas y campesinas, las sentencias de la Corte están asociados a la protección de derecho a la participación política y la protección del derecho a la consulta previa95. La Corte ha protegido y dado contenido al derecho a la alimentación como parte del trabajo y la libertad de profesión y oficio, en relación con el oficio de pesca artesanal. Este último tiene para aquellas comunidades dos dimensiones: es fuente de ingresos y garantía de su derecho a la alimentación ${ }^{96}$. Sobre la naturaleza del derecho a la alimentación ha sostenido la Corte que se trata de un derecho fundamental, de especial protección para las comunidades rurales que subsisten del cultivo, producción y distribución de alimentos obtenidos de la naturaleza. ${ }^{97}$

La Corte también se ha pronunciado sobre el derecho a la alimentación como parte del derecho al agua. Dentro de los componentes de este está la disponibilidad que supone el abastecimiento de agua para la satisfacción de las necesidades físicas de alimentación y salubridad. De allí que el derecho a la alimentación resulta quebrantado por la falta de agua a la que resultan sometidas las comunidades ${ }^{98}$.

De acuerdo con lo descrito, afirmamos que la función judicial se constituye en un medio a través del cual el Estado cumple su función de protección del derecho a la alimentación. De ahí que, además de la aplicación e interpretación de la norma, la función judicial se refiera a la determinación de reglas sobre la creación y aplicación del derecho en situaciones de vulneración.

${ }^{94}$ Corte Constitucional de Colombia, Sentencia T-714 (1996).

${ }^{95}$ Cfr. Galván-Tello, et al. (2018).

${ }^{96}$ Corte Constitucional de Colombia, Sentencia T-348 (2012), párr. 2.5.1.

${ }^{97}$ Corte Constitucional de Colombia, Sentencia T-348 (2012), párr. 2.5.7. y 2.5.8.

${ }^{98}$ Corte Constitucional de Colombia, Sentencia T-256 (2015) párr. 172. 


\section{Bases para una defensa de la justiciabilidad de los derechos sociales}

La discusión sobre la justiciabilidad de los derechos sociales en general, y el derecho a la alimentación en particular, se encuentra relacionada con su satisfacción, que implica la disposición de mecanismos de garantía y protección. Estos conceptos son autónomos pero interdependientes del concepto de derecho subjetivo. De su autonomía basta comprender que la categoría derecho subjetivo implica el reconocimiento jurídico de un bien o servicio en atención a su trascendencia para la satisfacción de necesidades. Por garantía se entiende la obligación de crear condiciones de posibilidad materiales para el ejercicio de los derechos. Por protección la obligación de disponer de mecanismos para determinar la responsabilidad y las reparaciones por su violación. Por justiciabilidad la posibilidad que tienen los titulares de los derechos de acudir ante los poderes de control para exigir la satisfacción de sus derechos — de esta suerte, no se reduce exclusivamente a la protección judicial, sino que incluye competencias de protección en cabeza de órganos cuasi jurisdiccionales o administrativos— ${ }^{99}$.

De su interdependencia cabe anotar que el nivel de eficacia de un derecho - densidaddepende, entre otras, de los instrumentos establecidos para su exigibilidad. Lo anterior no significa que la ausencia de mecanismos de garantía o protección implique necesariamente la inexistencia del derecho. Significa, sí, que se aumenta la brecha estructural entre normatividad y efectividad ${ }^{100}$. A esto fenómeno lo denominamos densidad del derecho, y su análisis contribuye a valorar y representar la magnitud de estas brechas.

Dado el debatido carácter justiciable de los derechos sociales y, en consecuencia, del derecho a la alimentación, se propone discutir argumentos que contribuyen a la vigencia de la tesis de que aquellos son meros principios rectores o cláusulas programáticas, derivando en la idea de que los poderes de control tienen proscrito protegerlos. Esta revisión crítica permitirá reivindicar el carácter exigible del derecho a la alimentación. Se enfatiza que poco sentido tiene hablar del contenido de estos derechos y sus mecanismos de garantía y protección si los principales llamados a su defensa - los poderes públicos- perseveran algunos argumentos para desatender su justiciabilidad.

${ }^{99}$ Cfr. Abramovich y Courtis (2002) y Langford (2009).

${ }^{100}$ Ferrajoli (2001). 


\subsection{Revisión crítica a los argumentos generacional y estructural que niegan la justiciabilidad de los derechos sociales}

Son dos, básicamente, los argumentos que niegan la justiciabilidad de los derechos sociales: el (i) generacional y el (ii) estructural. Estos últimos se desarrollan en 5 razones a partir de la relación entre derechos civiles y políticos-derechos sociales y económicos: universalesparticulares, absolutos-relativos, definitivos-prima facie, baratos-costosos y justiciablesprogramáticos 101.

El generacional (i) indica que históricamente los derechos sociales se consideran de creación posterior a la de los derechos civiles y políticos. Esto le otorga un carácter prescriptivo a la protección de estos: primero ha de garantizarse la protección de los derechos de primera generación —civiles y políticos - y posteriormente la protección de los de segunda —sociales. Así, en aquellos lugares donde “[...] los derechos sociales no se hubieran materializado, bastaría con confiar en el inexorable impulso de la evolución histórica, de la lógica garantista o del crecimiento económico para que ello acabe por ocurrir"102.

En contra de este argumento se señala que erróneamente parte de una interpretación en exceso lineal de la historia de los derechos y desconoce la interdependencia entre derechos sociales y derechos civiles y políticos. En efecto, la tesis identifica el surgimiento de los derechos sociales con su consagración positiva en las constituciones de Querétaro -México en 1917-y Weimar -Alemania en 1919-, y en instrumentos internacionales y constituciones de la segunda posguerra. Con ello sugieren que la existencia de los derechos sociales dependió de su reconocimiento por la vía institucional, una vez se encontraban satisfechos o en un buen grado de estabilidad los derechos civiles y políticos. Sin embargo, la historia de los DDHH es más compleja.

Se reconoce que desde la perspectiva formal estos derechos adquirieron una presencia generalizada en diversas fuentes normativas en la segunda mitad del siglo XX. Sin embargo, no puede prescindirse de las otras vías institucionales y no institucionales que reconocieron prestaciones en favor de los desprotegidos ni del valor material de las reivindicaciones sociales iniciadas con las revoluciones de mediados del siglo XIX. Debe considerarse que históricamente existieron mecanismos institucionales diferentes de tratados o constituciones. Así, políticas de

${ }^{101}$ Cfr. Hierro (2017).

102 Pisarello (2007), p. 15. 
orden público y mecanismos no institucionales dirigidos a reparar situaciones extendidas de pobreza y asistir a los colectivos más necesitados otorgaron reconocimiento de los derechos sociales. La ayuda a pobres, que estuvo motivada por la discrecionalidad de las autoridades y de los particulares amparados por un sentimiento de "beneficencia" y "caridad", se transformó posteriormente en beneficios concretos correspondientes a derechos sociales.

Tampoco es aceptable el postulado según el cual un requisito indispensable para la garantía y protección de los derechos sociales es que los derechos civiles y políticos estén satisfechos. Entre otras razones, dicha tesis desconoce abiertamente que el ejercicio real de los derechos civiles y políticos está condicionado por la satisfacción de los derechos sociales. La cuestión se comprende bajo el concepto de interdependencia entre derechos, y ha sido parte de la doctrina de las Naciones Unidas ${ }^{103}$, premisa esencial para interpretar y garantizar plenamente los DDHH. Piénsese e.g., que la medida estatal de proveer alimentos en cantidad y calidad suficiente a un sujeto en manifiesto estado de malnutrición satisface además del derecho a la alimentación, la mayoría de los derechos civiles y políticos cuyo sustrato material compromete el despliegue de actividades físicas por parte del individuo, como la libertad de locomoción.

El segundo argumento establecido por objetores de la justiciabilidad de los derechos sociales dispone que existe una tajante diferencia estructural entre estos y los derechos civiles y políticos (ii). Esta diferencia justifica que los ordenamientos jurídicos contemporáneos hayan otorgado una protección menor a los últimos. La diferencia puede sintetizarse en dos aspectos: las obligaciones que derivan de ellos y la vaguedad de sus enunciados. Primeramente, los derechos sociales aparecerían como derechos positivos, esto es, como generadores de prestaciones de dar o hacer por parte del Estado. Los derechos civiles y políticos, por su parte, generarían exclusivamente obligaciones negativas o de abstención. En virtud de sus obligaciones, los derechos civiles y políticos resultarían baratos y de fácil garantía y protección, mientras los sociales serían costosos y condicionados a lo económicamente posible o razonable. En segundo lugar, los derechos sociales, a diferencia de los derechos civiles y políticos, serían derechos vagos e indeterminados que dificulta la identificación de las prestaciones debidas y de los sujetos obligados.

En relación con el postulado que argumenta una diferencia de tipo obligacional entre los derechos civiles y políticos (derechos a abstenciones) y los derechos sociales (derecho a

${ }^{103}$ Cfr. Naciones Unidas (2006), p. 2 y Naciones Unidas (2016). 
prestaciones), afirmamos que parte del error conceptual de caracterizar a los primeros como derechos negativos y a los segundos como positivos ${ }^{104}$. En realidad, todos los derechos tienen una dimensión negativa y una dimensión positiva ${ }^{105}$. Estas imponen obligaciones de abstención -respeto-y prestación - garantía- a los poderes públicos. Los derechos civiles y políticos traen consigo obligaciones prestacionales derivadas de su función distributiva —así, la función social de la propiedad privada incorporada en el constitucionalismo social de principios del siglo XX. En el caso colombiano, prevista por el artículo 58 de la Constitución Política一, y los derechos sociales obligaciones de abstención. Para el caso colombiano, e.g., la Constitución Política prevé en su artículo 51 el derecho a la vivienda digna. En esta disposición se imponen al Estado un conjunto de obligaciones de carácter prestacional: fijar las condiciones necesarias para hacer efectivo el derecho y promover planes de vivienda de interés social, sistemas adecuados de financiación a largo plazo y formas asociativas de ejecución de programas de vivienda. Sin embargo, el contenido del derecho a la vivienda incluye el derecho a no-confiscación —artículo 34 constitucional-, a no ser expropiado sin previa indemnización -artículo 58 constitucional- y a no ser víctima de cláusulas abusivas en los contratos de arrendamiento Ley 820 de 2003-.

En relación con el derecho a la alimentación, este impone múltiples deberes negativos. Su componente de disponibilidad alimentaria impone al Congreso y a los particulares la obligación de abstenerse de crear normas o cláusulas contractuales que promuevan la inmunidad de los distribuidores o productores frente a los daños causados por los defectos en la producción de alimentos. Asimismo, su componente accesibilidad a los alimentos impone obligaciones esencialmente negativas, como: la prohibición de discriminación ${ }^{106}$, dirigida a impedir que autoridades y particulares utilicen motivos constitucionalmente prohibidos para no garantizar una alimentación adecuada; el deber de las autoridades y particulares de no entorpecer con sus acciones el acceso de la población a los alimentos.

Por otra parte, existe una prestación negativa común a todos los derechos sociales: la prohibición de regresión. Esta constituye el correlato de la obligación estatal de implementación progresiva de los derechos sociales. Los Estados se obligan a adoptar medidas domésticas y de cooperación internacional necesarias, hasta el máximo de los recursos disponibles, con el

${ }^{104}$ Cfr. Cranston (1967; 1962), Morales (2015), p. 85 y Plant (citado por Espada, 1996, pp. 104-105)

${ }^{105} \mathrm{Cfr}$. Holmes y Sunstein (2011).

${ }^{106}$ Cfr. Abramovich y Courtis (2006), p. 48. 
objetivo de lograr el desarrollo progresivo y la plena efectividad de los DESC107. Correlativamente a esa obligación quedan limitados para derogar y reducir los niveles cuantitativos y cualitativos de satisfacción de los derechos ${ }^{108}$. Con todo, esta obligación no ha de predicarse en términos absolutos — como en general ninguna-. Excepcionalmente puede considerarse que una medida deliberadamente regresiva no sea por si misma inválida ni haga incurrir al Estado en responsabilidad internacional. Ello, siempre que la misma tenga la más cuidadosa consideración y se encuentre plenamente justificada: “[...] [atendiendo] a la totalidad de los derechos previstos en el Pacto -PIDESC - y en el contexto del aprovechamiento pleno del máximo de los recursos de que se dispone"109.

Habitualmente los detractores de la exigibilidad de los derechos sociales argumentan que estos tienen un carácter intrínsecamente vago e indeterminado, que dificulta conocer con certeza lo que protegen, la medida en que lo hacen y los sujetos a quienes obligan. Al respecto, se sostiene que el grado de indeterminación y de vaguedad semántica es una característica inherente al lenguaje jurídico. Es una exigencia propia, y esperada, de las normas más generales del ordenamiento, las normas constitucionales ${ }^{110}$.

Sin embargo, los detractores insisten en una indeterminación particular que afecta los derechos sociales. Aducen que, si bien estos derechos comportan algunas obligaciones de resultado ( $v$. gr. garantizar una alimentación adecuada), los medios específicos a través de los cuales se daría cumplimiento a las mismas serían absolutamente indeterminados. Lo anterior representaría una diferencia estructural frente a los derechos civiles y políticos, dado que estos, además de establecer el objetivo que pretenden perseguir, indicarían, como mínimo, prohibiciones relativas a aquellos actos que implicarían su vulneración ${ }^{111}$ (v. gr. El derecho a la vida es inviolable, ergo no habrá pena de muerte).

No consideramos acertada esta contraposición entre los derechos sociales y los derechos de libertad por dos motivos. En primer lugar, realmente nada autoriza a inferir que conceptos como "libertad de expresión", "igualdad", "intimidad personal” o "propiedad" sean más precisos o menos indeterminados que conceptos como "nivel adecuado de alimentación", "vivienda digna" o "educación". De ahí que determinar las conductas que bajo aquellos conceptos se encuentran

\footnotetext{
107 Artículos 2 del PIDESC (1966) y Protocolo de San Salvador (1988).

108 Cfr. Arango (2006).

${ }^{109}$ Comité de Derechos Económicos, Sociales y Culturales (1990), párr. 9.

${ }^{110}$ Cfr. Morales (2015), Pintore (2001), Waldron (1994) y Sumner (1987).

111 Bernal (2005), p. 116.
} 
protegidas o prohibidas no sea labor sencilla. En consecuencia, afirmar que "cualquier tipo de conducta" puede verse incluida dentro de la prestación de abstención que deriva de un derecho de libertad, no es más que un sofisma del consecuente.

\section{Conclusiones}

Revisados los argumentos teóricos más utilizados para defender una distinción en la justiciabilidad entre los derechos sociales y los derechos civiles y políticos, presentamos argumentos en contrario. Sostenemos desde una posición garantista que existen fundamentos para la exigibilidad plena y amplia de los derechos sociales, en especial, del derecho a la alimentación. Sostenemos que, en virtud de su reconocimiento, los derechos tienen contenidos positivos y negativos e imponen obligaciones de abstención — respeto- y prestación garantía- Y Y de la vulneración de cualquiera de estas deriva la obligación de protección. Todos los derechos conllevan obligaciones positivas y por ello son costosos, en tanto demandan del Estado la realización de ciertas acciones que se traducen en la adopción de mecanismos en cumplimiento de las obligaciones de garantía y protección, cuyo funcionamiento requiere la asignación y gasto de fondos públicos.

A partir de una visión crítica de las clasificaciones de derechos, sostenemos que los argumentos en contra de la exigibilidad de los derechos sociales han partido de argumentaciones erróneas. La tesis que relega la satisfacción de los derechos sociales al devenir histórico representa una lectura en exceso lineal de la historia de los derechos y desconoce la interdependencia que existe entre los derechos sociales y los civiles y políticos. Aunado a lo anterior, demostramos que los derechos civiles y políticos, y los sociales conservan una estructura comparable. Por ello la concepción de los segundos como exclusivamente prestacionales y la objeción del costo excesivo de los mismos, resultan insostenibles para negar la justiciabilidad de los derechos sociales.

Desarrolladas las bases que fundamentan el carácter exigible de los derechos sociales, la tarea que resulta radica en delimitar los mecanismos existentes para su defensa. A partir del derecho a la alimentación en Colombia se procedió a delimitar los medios de defensa internacionales e internos para su protección. En el Sistema Universal estos mecanismos de protección son bastante limitados. Situación distinta sucede en el Sistema Interamericano, donde los pronunciamientos de la Corte IDH han declarado la violación y ordenado la protección de 
derechos sociales, e.g. el derecho a la alimentación de indígenas, personas privadas de la libertad y desplazados. Así mismo, demostramos que en el ordenamiento jurídico colombiano la protección judicial de los derechos sociales es posible también en el caso del derecho a alimentación. Se observa que la protección del derecho a la alimentación se da de manera directa, advirtiendo la necesidad de proteger el derecho, o indirecta, protegiendo el derecho a partir de su conexidad con un derecho distinto.

Superar la discusión es lo que proponemos por medio del concepto analítico "densidad de los derechos". Este permite integrar elementos fácticos, jurídicos y dogmáticos al análisis de la satisfacción de los derechos. A partir de la revisión de la literatura sobre la justiciabilidad de derechos sociales, la reconstrucción y propuesta de argumentos en favor de esta y la descripción de los mecanismos de protección en los sistemas Universal, Interamericano e interno de protección de derechos, proponemos un marco de referencia teórico y metodológico para el estudio de la densidad de los derechos. El marco teórico ofrece una relación entre los contenidos constitucionales, las competencias de los poderes públicos, el régimen de derechos y las vías para su satisfacción. Por su parte, el metodológico relaciona los elementos fácticos de un derecho con sus elementos jurídicos, a partir de los acuerdos respecto de sus elementos dogmáticos.

\section{Bibliografía citada}

Abramovich, Víctor, y Courtis, Christian (2002): Los derechos sociales como derechos exigibles (Madrid, Trotta).

(2006): El umbral de la ciudadanía. El significado de los derechos sociales en el Estado social constitucional (Buenos Aires, Editores del Puerto).

Alexy, Robert (1993): Teoría de los derechos fundamentales. (Ernesto Garzón Valdés, Trad.) (Madrid, Centro de Estudios Constitucionales).

Arango, Rodolfo (2006): “La prohibición de retroceso en Colombia”, en Christian Courtis (Ed.), Ni un paso atrás: la prohibición de regresividad en materia de derechos sociales (Buenos Aires, Del Puerto) pp. 153-172. 
Bernal Pulido, Carlos (2005): "Fundamento, concepto y estructura de los derechos sociales. Una crítica a "¿Existen derechos sociales?" de Fernando Atria” en Discusiones: Derechos Sociales $\left(\mathrm{N}^{\circ} 4\right)$, pp. 99-144.

Carbonell, Miguel (2008): “Eficacia de la constitución y derechos sociales: esbozo de algunos problemas", en Estudios Constitucionales (Año 6, № 2), pp. 43-71.

Cranston, Maurice (1962): Human Rights, Real and Supposed (New York, Basic Books). (1967): “Human Rights, Real and Supposed”, en D. D. Raphael, Political Theory and the Rights of Man (Bloomington, Indiana University Press) pp. 43-54.

Cruz Parcero, Juan Antonio (2007): El lenguaje de los derechos (Madrid, Editorial Trotta).

Departamento Administrativo Nacional de Estadística (s.f.). "Defunciones No Fetales". [Disponible en: https://bit.ly/3DlestK]. [Fecha de consulta: 15 de junio de 2019].

Duque Quintero, Sandra Patricia, González Sánchez, Flor Patricia, Cossio Acevedo, Nora Alba, y Martínez Monsalve, Sandra María (2018): Investigación en el saber jurídico (Medellín, Editorial Universidad de Antioquia).

Espada, Joao Carlos (1996): Derechos sociales del ciudadano (Madrid, Acento Editorial).

Ferrajoli, Luigi (1995): Derecho y razón. Teoría del garantismo penal (Madrid, España: Editorial Trotta, S.A).

(2001): "Derechos Fundamentales", en A. de Cabo, y G. Pisarello (Edits.), Los fundamentos de los derechos fundamentales (Madrid, Trotta) pp. 19-56.

(2007): Principia iuris. Teoría del derecho y de la democracia. 2. Teoría de la democracia, (A. Ruíz-Miguel, y P. A. Ibáñez, Trads.) (Bologna, Italia: Trotta).

(2008): "La esfera de lo indecidible y la división de poderes", en Estudios Constitucionales (Año 6, Nº 1), pp. 337-343.

Fioravanti, Maurizio (2014): Constitucionalismo. Experiencias históricas y tendencias actuales (Madrid, España, Editorial Trotta). 
Friedman, Milton (1962): Capitalism and Freedom (Chicago, University of Chicago Press).

Galván-Tello, María del Carmen, Molina-Saldarriaga, César Augusto, Restrepo-Yepes, Olga Cecilia, Cataño-Gómez, Paola Andrea y Restrepo-Yepes, Juan Diego (2018): “Participación democrática y garantía de los derechos humanos. Un análisis de la protección del derecho a la alimentación en sede judicial constitucional a través de la protección del derecho a la participación ciudadana en Colombia y México" en L. E. Ríos-Vega, I. Spigno, y M. Y. RoblesGarza (Edits.), Los derechos Fundamentales en el Siglo XXI. Tomo II El Estudio Comparado. Estudios de casos líderes nacionales. Los Derechos Humanos en la Jurisprudencia de la Suprema Corte de Justicia de la Nación (Ciudad de México, México, Tirant Lo Blanch) pp. 299334.

Golay, Christophe (2009): Derecho a la Alimentación y Acceso a la Justicia: Ejemplos a nivel nacional, regional e internacional (Roma, Organización de las Naciones Unidas para la Agricultura y la Alimentación).

Hamulák, Ondrej, Troitiño, David Ramiro, y Chochia, Archil (2018): “La carta de los derechos fundamentales de la Unión Europea y los derechos sociales" en Estudios Constitucionales (Año 16, $\mathrm{N}^{\circ}$ 1), pp. 167-186.

Hayek, Friedrich Von (1979): Derecho, legislación y libertad (Madrid: Unión), Vol. II.

Hierro, Liborio (2017): “Los derechos económico-sociales y el principio de igualdad en la teoría de los derechos de Robert Alexy", en R. Alexy, Derechos sociales y ponderación (México, D. F., Editorial Fontamara) pp. 163-222.

Holmes, Stephen y Sunstein, Cass (2011): El costo de los derechos. Por qué la libertad depende los impuestos (Buenos Aires, Siglo Veintiuno editores).

Instituto Colombiano de Bienestar Familiar (2006). "Encuesta Nacional de la Situación Nutricional en Colombia, 2005. [Disponible en: https://bit.ly/3wExhFY]. [Fecha de consulta: 15 de junio de 2019].

(2011): Encuesta Nacional de la Situación Nutricional en Colombia (ENSIN) 2010. (Bogotá, Instituto Colombiano de Bienestar Familiar). 
(2020): Encuesta Nacional de la Situación Nutricional ENSIN 2015 (Bogotá: Instituto Colombiano de Bienestar Familiar). [Disponible en: https://bit.ly/3wDQast]. [Fecha de consulta: 30 de septiembre de 2020].

Langford, Malcolm (2009): "Justiciabilidad en el ámbito nacional y los derechos económicos, sociales y culturales: un análisis socio-jurídico", en Sur. Revista Internacional de Derechos Humanos (Vol. 6, $\left.\mathrm{N}^{\circ} 11\right)$, pp. 99-133.

Martínez-Estay, José Ignacio (2010): “Los derechos sociales de prestación en la jurisprudencia chilena", en Estudios Constitucionales (Año 8, №2), pp. 125-166.

Morales, Leticia (2015): Derechos sociales constitucionales y democracia (Madrid, Marcial Pons).

Naciones Unidas (2006): Preguntas frecuentes sobre el enfoque de derechos humanos en la cooperación para el desarrollo, (Nueva York y Ginebra: Naciones Unidas. Oficina del Alto Comisionado de las Naciones Unidas para los Derechos Humanos).

(2016): Derechos Humanos. Manual para Parlamentarios N²6, (Ginebra, Suiza, Naciones Unidas. Oficina del Alto Comisionado para los Derechos Humanos. Unión Interparlamentaria).

Nash-Rojas, Claudio (2011): "Los derechos económicos, sociales y culturales y la justicia constitucional latinoamericana: tendencias jurisprudenciales", en Estudios Constitucionales (Año 9, N 1), pp. 65-118.

Nogueira-Alcalá, Humberto (2009): "Los derechos económicos, sociales y culturales como derechos fundamentales efectivos en el constitucionalismo democrático latinoamericano", en Estudios Constitucionales (Año 7, № 2), pp. 143-205.

(2010): "La protección de los derechos sociales como derechos fundamentales de eficacia inmediata justiciables en jurisdicción constitucional”, en Estudios Constitucionales (Año 8, N²), pp. 763-798.

Nozick, Robert (1974): Anarquía, Estado y utopía (Estados Unidos, Basic Books). 
Organización de las Naciones Unidas para la Agricultura y la Alimentación (2004): Directrices Voluntarias. En apoyo de la realización progresiva del derecho a una alimentación adecuada en el contexto de la seguridad alimentaria nacional (Roma, Italia, Organización de las Naciones Unidas para la Agricultura y la Alimentación).

Pachot, Karel (2010): “A propósito del carácter fundamental de los derechos económicos, sociales y culturales. Una mirada desde la doctrina comparada y la experiencia del ordenamiento jurídico cubano", en Estudios Constitucionales (Año 8, № 1), pp. 13-42.

Pintore, Anna (2001): “Derechos insaciables" en G. Pisarello, y L. Baccelli (Edits.), Los fundamentos de los derechos fundamentales (Madrid, Trotta) pp. 243-265.

Pisarello, Gerardo (2007): Los derechos sociales y sus garantías. Elementos para una reconstrucción (Madrid, Trotta).

Real Academia Española (2019). [Disponible en: https://dle.rae.es]. [Fecha de consulta: 23 de abril de 2020].

Solari, Enzo y Viera, Christian (2015): “Justiciabilidad de los derechos sociales (a propósito de una argumentación de Fernando Atria)”, en Estudios Constitucionales (Año 13, №2), pp. 1356.

Sumner, Leonard Wayne (1987): The Moral Foundation of Rights (Oxford, Oxford University Press).

Waldron, Jeremy (1994): "Vagueness in Law and Language: Some Philosophical Issues", en California Law Review (Vol. 82, № 1), pp. 509-540.

Wunder-Hachem, Daniel (2014): “Derechos fundamentales económicos y sociales y la responsabilidad del Estado por la omisión”, en Estudios Constitucionales (Año 12, № 1), pp. 285-328.

\section{Normas jurídicas citadas}

Comité de Derechos Económicos, Sociales y Culturales. Observación General N. 12 . El derecho a una alimentación adecuada. Ginebra: E/C.12/1999/4, 12 de mayo de 1999. 
Comité de Derechos Económicos, Sociales y Culturales. Observación general 3, La índole de las obligaciones de los Estados Partes (párrafo 1 del artículo 2 del Pacto). New York: Comité de Derechos Económicos, Sociales y Culturales, 14 de diciembre de 1990.

Consejo Económico y Social de las Naciones Unidas. Resolución 1985/17. Revisión de la composición, organización y arreglos administrativos del Grupo de Trabajo de Expertos Gubernamentales sobre la Implementación del Pacto Internacional de Derechos Económicos, Sociales y Culturales, 28 de mayo de 1985.

Corte Interamericana de Derechos Humanos. Opinión Consultiva OC-23/17. Medio ambiente y derechos humanos, 15 de noviembre de 2017.

Constitución Política de Colombia. (1991). Bogotá D.C., Colombia: Asamblea Nacional Constituyente.

Ley 1257, por la cual se dictan normas de sensibilización, prevención y sanción de formas de violencia y discriminación contra las mujeres, se reforman los Códigos Penal, de Procedimiento Penal, la Ley 294 de 1996 y se dictan otras disposiciones. Diario Oficial. Año CXLIV. N. 47193. 4, diciembre, 2008. pág. 1, Bogotá D.C., Colombia.

Ley 820, por la cual se expide el régimen de arrendamiento de vivienda urbana y se dictan otras disposiciones. Diario Oficial N.o 45.244, de 10 de julio de 2003, Bogotá, D. C., Colombia.

Naciones Unidas. Protocolo Facultativo del Pacto Internacional de Derechos Económicos, Sociales y Culturales. Resolución 217 A (III). New York: Naciones Unidas, 10 de septiembre de 2008.

Naciones Unidas. Pacto Internacional de Derechos Económicos, Sociales y Culturales. Resolución 2200 A (XXI). Nueva York: Naciones Unidas, 16 de diciembre de 1966.

Naciones Unidas. Convención sobre la eliminación de todas las formas de discriminación contra la mujer. Ginebra: Resolución 34/180, 1979.

Naciones Unidas. Convención sobre los Derechos del Niño. New York: Resolución 44/25, 1989. 
Naciones Unidas. Protocolo Facultativo de la Convención sobre la eliminación de todas las formas de discriminación contra la mujer. Resolución A/54/4. Nueva York: Naciones Unidas, 6 de octubre de 1999.

Naciones Unidas. Observaciones generales aprobadas por el Comité de Derechos Económicos, Sociales y Culturales, 2016. (0. d. Ginebra, Editor) Recuperado el 18 de junio de 2019, de https://conf-

dts1.unog.ch/1\%20SPA/Tradutek/Derechos_hum_Base/CESCR/00_1_obs_grales_Cte\%20 Dchos\%20Ec\%20Soc\%20Cult.html

Organización de Estados Americanos. Protocolo Adicional a la Convención Americana sobre derechos humanos en materia de derechos económicos, sociales y culturales "Protocolo de San Salvador". San Salvador, El Salvador: Organización de Estados Americanos, 17 de noviembre de 1988.

Organización de Estados Americanos. Declaración Americana de Derechos y Deberes del Hombre. Bogotá, Colombia, 1948.

Organización de Estados Americanos. Convención Americana de Derechos Humanos. San José, Costa Rica: Organización de Estados Americanos, 1969.

\section{Jurisprudencia citada}

\section{Corte Interamericana de Derechos Humanos:}

Corte Interamericana de Derechos Humanos: Caso Comunidad indígena Yakye Axa Vs. Paraguay (Sentencia de 17 de junio de 2005 Fondo, Reparaciones y Costas), 17 de junio de 2005.

Corte Interamericana de Derechos Humanos: Caso Montero Aranguren y otros (Retén de Catia) Vs. Venezuela (Sentencia Excepción Preliminar, Fondo, Reparaciones y Costas), 5 de julio de 2006.

Corte Interamericana de Derechos Humanos: Caso Vélez Loor vs. Panamá (Sentencia Excepciones Preliminares, Fondo, Reparaciones y Costas), 23 de noviembre de 2010. 
Corte Interamericana de Derechos Humanos: Caso Pacheco Teruel y otros vs. Honduras (Sentencia Fondo, Reparaciones y Costas), 27 de abril de 2012.

Corte Interamericana de Derechos Humanos: Caso de las Comunidades afrodescendientes desplazadas de la cuenca del río Cacarica (Operación Génesis) Vs. Colombia (Sentencia Excepciones Preliminares, Fondo, Reparaciones y Costas), 20 de noviembre de 2013.

Corte Interamericana de Derechos Humanos: Caso comunidades indígenas miembros de la Asociación Lhaka Honhat (Nuestra Tierra) Vs. Argentina, Sentencia (Fondo, Reparaciones y Costas), 6 de febrero de 2020.

\section{Corte Constitucional de Colombia:}

Corte Constitucional: Sentencia C-010 (Acción de inconstitucionalidad), 23 de enero de 2013.

Corte Constitucional: Sentencia C-053 (Acción de inconstitucionalidad), 10 de febrero de 2016.

Corte Constitucional: Sentencia C-077 (Acción de inconstitucionalidad), 8 de febrero de 2017.

Corte Constitucional: Sentencia C-1200 (Acción de inconstitucionalidad), 9 de diciembre de 2003.

Corte Constitucional: Sentencia C-153 (Acción de inconstitucionalidad), 7 de marzo de 2007.

Corte Constitucional: Sentencia C-255 (Acción de inconstitucionalidad) 25 de marzo de 2003.

Corte Constitucional: Sentencia C-288 (Acción de inconstitucionalidad), 18 de abril de 2012.

Corte Constitucional: Sentencia C-371 (Acción de inconstitucionalidad), 11 de junio de 2014.

Corte Constitucional: Sentencia C-579 (Acción de inconstitucionalidad), 28 de agosto de 2013.

Corte Constitucional: Sentencia C-588 (Acción de inconstitucionalidad), 27 de agosto de 2009.

Corte Constitucional: Sentencia T-008 (Revisión de tutela), 18 de mayo de 1992.

Corte Constitucional: Sentencia T-029 (Revisión de tutela), 19 de enero de 2001.

Corte Constitucional: Sentencia T-049 (Revisión de tutela), 15 de febrero de 1995. 
Corte Constitucional: Sentencia T-1031 (Revisión de tutela), 21 de octubre de 2004.

Corte Constitucional: Sentencia T-179 (Revisión de tutela), 7 de mayo de 1993.

Corte Constitucional: Sentencia T-256 (Revisión de tutela), 15 de mayo de 2015.

Corte Constitucional: Sentencia T-339 (Revisión de tutela), 25 de agosto de 1993.

Corte Constitucional: Sentencia T-348 (Revisión de tutela), 15 de mayo de 2012.

Corte Constitucional: Sentencia T-373 (Revisión de tutela), 22 de julio de 1998.

Corte Constitucional: Sentencia T-424 (Revisión de tutela), 24 de junio de 1992.

Corte Constitucional: Sentencia T-426 (Revisión de tutela), 24 de junio de 1992.

Corte Constitucional: Sentencia T-523 (Revisión de tutela), 7 de julio de 2006.

Corte Constitucional: Sentencia T-714 (Revisión de tutela), 16 de diciembre de 1996. 